Habida cuenta de que ésta que doy a conocer es de momento la única muestra de su trabajo, y más aún cuando no alcanzó realización efectiva (hasta donde podemos saber; de hecho, ni siquiera podemos estar seguros de que se proyectó que la tuviera), está claro que no será con ella que Gabino González Velázquez dejará de ser poco más que un nombre en la historia del grabado en hueco en España. Pero es, repito, precisamente por ese nombre suyo, tanto como por la posibilidad de darle cuerpo histórico y situarlo con alguna claridad en el horizonte de los grabadores de su tiempo, por lo que conviene reunir cuanto sea posible acerca de su persona. Hay que insistir en la importancia de perfilar la biografía y labor de estos artistas, también de las figuras secundarias, si alguna vez va a ser posible confeccionar un relato histórico, sobre cimientos sólidos, de la medalla española del siglo XIX.

José Luis ARIAS Bonel

\title{
CAPUT SANCTI IHOHANIS BAPTISTE IN DISCO EN UN ALABASTRO GÓTICO INGLÉS DE LA ANTIGUA COLECCIÓN MASSÓ
}

Entre los fondos museográficos de la antigua colección particular de la familia Massó, conocida sobre todo por su colección etnográfica, sorprende la presencia de una interesante placa gótica de alabastro inglés de pequeñas dimensiones que, sin tratarse de una pieza de extraordinaria calidad, por su iconografía es obra de gran interés ${ }^{1}$.

La pieza responde al tipo conocido con el nombre de Cabezas de San Juan ${ }^{2}$. Concebida como obra única y no como parte constituyente de un retablo, está tallada en un altorrelieve que muestra la cabeza de San Juan Bautista dispuesta sobre una bandeja circular, debajo de la cual, con unas dimensiones menores, figura la imagen de Cristo resucitado saliendo del sepulcro, con su mano derecha colocada sobre la herida abierta en el costado, y la izquierda, mutilada, en actitud de intentar levantarla ${ }^{3}$ (Fig. 1).

El relieve, que llegó hasta nuestros días bastante fragmentado, denuncia su factura inglesa. En efecto, estilísticamente hablando, la talla constituye un reflejo desvirtuado de los modelos de Cabezas de San Juan Bautista que habían introducido los talleres ingleses a comienzos del siglo $\mathrm{xv}$, modelos que se distinguían por su alta calidad, ostensible en una cierta exquisitez y minuciosidad en el tratamiento de las formas y en la elaboración de los detalles. A partir de la segunda mitad del siglo xv la producción de alabastros entra en un proceso de

ción, aun en momentos en que la medallística oficial quedaba en gran parte en manos francesas. No eran pocas las dificultades técnicas y económicas en España para el grabado de medalla en la época de Gabino Velázquez. Imposible competir en técnica, maquinaria y riqueza de diseño con Francia, hacia donde se dirigió la iniciativa española. Mejor producto y más barato, como aún reconocía, mucho tiempo después y con cierta amargura, un erudito entusiasta (Castellanos, Basilio Sebastián, El progreso en las Bellas Artes. Estudio de esculto-grabado y grabado comercial e industrial fundado por D. Victorino González y Fernández, Madrid, 1880, pp. 17-18).

\footnotetext{
${ }^{1}$ Esta pieza se conserva actualmente en el recién creado Museo Massó (Bueu, Pontevedra), en donde ingresó fruto de la compra que la Xunta de Galicia realizó en el año 1995 de la antigua colección de la familia Massó.

${ }^{2}$ Sobre estas piezas, denominadas Cabezas de San Juan véase Hope, W.H.: «On the sculptured alabaster tablets called Saint John's Heads», Archeologia, LII, 1890; Cheetham, F.W.: Medieval English alabaster carvings in the Castle Museum Nottingham, Nottingham: Ed. Derry and sons limited, 1962, p. 49-50; idem, 1984, pp. 317-332; Idem, English Medieval Alabasters. With a Catalogue of Collection in the Victoria and Albert Museum, Oxford: Ed. Phaidon Press Limited, 1984, pp. 317-332.

${ }^{3}$ Sus medidas son: alto: $27^{\prime} 5 \mathrm{~cm}$, largo: $14 \mathrm{~cm}$, y de ancho: $1 \mathrm{~cm}$. Su estado de conservación es bastante malo, ya que se encuentra fragmentada por la mitad. Está colocada sobre una peana de madera y sujeta a ambos lados por grapas metálicas.
}

AEA, LXXVII, 2004, 307, pp. 301 a 326 
fabricación industrializada; la causa ha de buscarse en la fuerte demanda de este tipo de piezas, que eran bien recibidas por su coste razonable, facilidad de transporte y grato efecto. El resultado fue la consecuente merma de calidad, perduración de formulismos y excesiva ausencia de iniciativas en la interpretación personal de los temas ${ }^{4}$.

Ciertamente, el tratamiento del relieve de la colección Massó denuncia una merma significativa de cualidades, visible de manera manifiesta en la talla del Bautista, despojada de los valores expresivos que poseían los primeros modelos; incluso, en la notación de la cabellera, concebida de una manera muy artificial, con una distribución en zonas incisas, muy uniforme. Podemos apreciar incluso cómo el remate ornamental de los mechones y la barba, elaborados con cierto barroquismo, deja paso a un acabado menos minucioso, así como en la constitución un tanto inorgánica del cuerpo de Cristo, casi inacabado, contando, posiblemente, con que el efecto final del conjunto se completara con la aplicación de la policromía. Por otro lado, incluso la simplicidad de la escena, reducida a los elementos iconográficos elementales, se mantiene muy alejada de la riqueza y complejidad iconográfica de los primeros modelos ${ }^{5}$. Indudablemente, todas estas características definen un estilo que, como hemos apuntado, denota el grado de desvirtualización al que sometieron los talleres de Nottingham hacia finales del siglo $\mathrm{xv}$ los modelos acuñados a comienzos del siglo anterior.

En efecto, la pieza muestra semejanzas compositivas y estilísticas con otros relieves procedentes de los talleres de Nottingham, especializados en la producción de pequeñas imágenes de devoción y de retablos de alabastro, como podemos observar en algunos de los ejemplares pertenecientes a la colección del Victoria and Albert Museum ${ }^{6}$ (figs.6,8) o en la interesante Cabeza de San Juan Bautista de la colección Alfonso Manrique de Lara ${ }^{7}$ (fig.5), fechados todos ellos hacia finales del siglo xv, lo que permitiría conjeturar una fecha similar para la talla Massó.

Algunas de estas singulares piezas exhiben, en el reverso, una serie de marcas, bien una numeración en el caso de placas que integran retablos más complejos y que indican la posición que el relieve debía ocupar en el conjunto, o, como ocurre en el caso de nuestro relieve, una referencia al tema representado. En el reverso de nuestro alabastro hemos podido valuar también la presencia de una serie de inscripciones; una primera inscripción, con un tratamiento bastante descuidado y los caracteres muy superficiales y en letra minúscula, en la que puede leerse la palabra Capu (Caput $=$ Cabeza) y una segunda inscripción, más cuidada y reiterando los mismos caracteres - Cap-. En la parte inferior se pueden apreciar otros caracteres prácticamente ilegibles que no nos permiten ofrecer una interpretación segura de su sentido o significado (Figs. 2-4).

Iconográficamente hablando, durante los siglos xIV y xv, la representación de la bandeja con la cabeza de San Juan Bautista, como apreció en su momento Panofsky, se había transformado en una imagen aislada de devoción popular especialmente en los países del norte de Europa y en el norte de Italia, desmembrándose de una representación de la historia de Salomé de una forma muy parecida a como el grupo de San Juan Evangelista descansando en el regazo de Cristo se había separado de la Última Cena ${ }^{8}$. Del fuerte arraigo de la devoción hacia

\footnotetext{
${ }^{4}$ Sobre el tema véase: Bouillet, A.: «La Fabrication industrielle des retables en albâtre (XIV-XV siècles)», Bulletin Monumental, 1901.

${ }^{5}$ En el análisis llevado a cabo por W.H. Hope, el autor, en función de su iconografía, reconoce seis grupos diferentes; según su clasificación, nuestra pieza se encuadraría en el cuarto grupo iconográfico o grupo D, organizado en torno a dos escenas: la imagen de la cabeza del Bautista sobre una bandeja centrando la composición, y debajo de ésta la figura de Cristo saliendo del sepulcro. Cheetham, F.W.: 1984, p. 317.

${ }^{6}$ Cheetham, F.W.: 1984, pp.326-327, 329, nº 250-251, 253

${ }^{7}$ Hernández Perera, J.: «Un alabastro gótico ingles», Archivo Español de Arte, n 116, t. XXIX, 1956, pp. 302-305; Cfr. Ídem, «Alabastros ingleses en España», Goya, $\mathrm{n}^{\circ} 22,1958$, pp. 216-222, esp. 221-222.

${ }^{8}$ Panofsky, E.: Estudios sobre iconología, Madrid: Ed. Alianza Universidad, 1972, pp.23, 39, fig. 4
}

AEA, LXXVII, 2004, 307, pp. 301 a 326 
estas Cabezas de San Juan Bautista en Inglaterra desde mediados del siglo xv es buena muestra la proliferación de este tipo de placas, unos objetos que, como confirman numerosos testimonios documentales de la época, fueron muy demandados como instrumentos de devoción privada y que encuentran su explicación en el marco de la promoción del culto a San Juan Bautista que desde finales del siglo XII, y sobre todo desde el siglo XII en adelante, cobra impulso en la ciudad de Nottingham y en zonas próximas a su área ${ }^{9}$. El tema se ajusta, además, a la iconografía que promovieron estos talleres en la elaboración de retablos y otras imágenes de devoción en las que podemos reconocer el gusto por una temática con cierta carga emocional como el ciclo de la Pasión de Nuestro Señor o los temas hagiográficos.

Otro relieve de alabastro empotrado actualmente en uno de los muros de la sacristía de Santa María la Real de Xunqueira de Ambía (Xunqueira de Ambía, Orense) pudo haber pertenecido también a esta serie ${ }^{10}$; si bien el estado de conservación de la pieza no permite proponer con total seguridad una hipótesis reconstructiva, en la iconografía de la escena conservada se puede reconocer una intención similar a la de otras series iconográficas de la Cabeza del Bautista (Fig. 7). Aunque muy distintos entre sí, el relieve orensano, de mayor complejidad y riqueza iconográfica, puede incluirse en el denominado grupo $\mathrm{E}$, quinto de los determinados por John Hope para las denominadas Cabezas de San Juan ${ }^{11}$. A pesar de que ha sido mutilado con el objeto de acoplarlo al frente de un antiguo sagrario, parece ajustarse a una de las variantes iconográficas que para este tema adoptaron los talleres de Nottingham a partir de la segunda mitad del siglo xv, en la que la figura del Bautista se hace acompañar de las efigies de santos o arzobispos; en efecto, la mayoría de los ejemplares conservados muestran a San Pedro acompañado de un arzobispo si bien en otros se recurre a santos populares (Figs. 5-6,8). En el relieve de Xunqueira la imagen de San Juan iría acompañada por San Pedro a su derecha y San Pablo a su izquierda. La imagen de San Pablo se ajusta bastante a los patrones acuñados por los talleres ingleses para la iconografía del apóstol como mártir; barbado, con la frente despejada y los cabellos cayendo sobre sus hombros, ataviado con una túnica y amplio manto y portando en su mano izquierda la espada. Por su parte, San Pedro, sin introducir variaciones respecto a su prototipo, se representa barbado, ataviado con manto y túnica, porta en su mano derecha las llaves y en la izquierda sostiene un libro cerrado ${ }^{12}$.

Ambas piezas viene a sumarse a la amplia serie de obras góticas inglesas de alabastro que llegaron a Galicia a partir mediados del siglo xv. Muchas de estas imágenes de devoción, más de las que hasta la fecha sospechamos, llegaron en una época en la que el tráfico marítimo entre Inglaterra y los principales puertos gallegos era muy intenso, en especial en los Años Santos con una máxima afluencia de peregrinos, y que alcanzaría su cenit en los años centrales del siglo Xv al amparo de la protección real y la de los señores jurisdiccionales ${ }^{13}$. En opinión de

\footnotetext{
${ }^{9}$ Cfr. Cheetham, F.W.: 1962, p. 49-50; Idem, 1984, pp. 317-332.

${ }^{10}$ Sobre este templo consúltense los siguientes trabajos: Vázquez Núñez, A.: «La ex - colegiata de Junquera de Ambía», Boletín de la Comisión Provincial de Monumentos Históricos y Artísticos de Orense, T. I, 1900; Alonso, F.B.: «Junquera de Ambía», Boletín de la Comisión Provincial de Monumentos Históricos y Artísticos de Orense, T. II, $\mathrm{n}^{\circ}$ 44, mayo-junio de 1905, pp. 345-350; Goddard King, G.: «Junquera de Ambía», American Journal of Archeology, 1923; Couceiro Freijomil, A.: «Monumentos de la provincia de Orense», Boletín de la Comisión Provincial de Monumentos Históricos y Artísticos de Orense, T. XI, 1936-1938; González García, M.A.: «Xunqueira de Ambía. Monasterio de Santa María la Real de», Gran Enciclopedia Gallega, T. 30, Gijón: Silverio Cañada editor, pp. 215-219.

${ }^{11}$ Cheetham, F.W.: 1984, p.318.

${ }^{12}$ Sobre la iconografía de ambos apóstoles en los alabastros medievales ingleses: Cheetham, F.W.: 1962, p. 44; Idem, 1984, pp. 135-142, nº 64-71.

${ }^{13}$ En el Año Jubilar de 1434, el rey Juan II de Castilla se dirigirá en la feria de Medina del Campo a todas las naciones de Europa ofreciendo salvoconductos a todos los peregrinos que se dirigieran a la tumba apostólica, tanto por tierra como por mar, que se pusieran bajo su protección. Véase sobre el tema el trabajo de Tate, B.: «Las peregrinaciones marítimas medievales desde las Islas Británicas a Compostela», en: Santiago, Camino de Europa. Culto y Cultura en la Peregrinación a Compostela, Santiago de Compostela, 1993, pp. 161-179. Es un testimonio elocuente el incidente acontecido en A
} 
Sánchez Ameijeiras, la peregrinación pudo constituir uno de los canales de entrada de este tipo de piezas de alabastro en nuestras tierras ${ }^{14}$, ya que, si bien, de toda la gente que llegaba en los barcos ingleses, los peregrinos eran los que menos papel tenían en los intercambios comerciales, las condiciones en las que hacían estos viajes les obligaban a operar como mercaderes para poder hacer frente a los gastos del viaje y a su estancia en Galicia, por lo que era frecuente que embarcaran una partida de mercancía entre la que posiblemente se incluiría algún objeto valioso para negociarla a su llegada.

No obstante, será a lo largo del siglo xvi cuando el comercio de alabastros entre Inglaterra y el continente alcance su momento álgido. El tráfico de este tipo de obras de arte se verá alentado como consecuencia del edicto inglés de prohibición de las imágenes religiosas, entre las que se menciona de forma específica los alabastros, y la terrible furia iconoclasta que acompañó la Reforma, con la consecuente pérdida de cuantiosos ejemplares. Por otro lado, los vaivenes políticos acontecidos entre los reinados de la reina María Tudor e Isabel I afectaron muy seriamente al comercio de exportación de estas obras, y con la prohibición de la explotación de las canteras para la talla de las esculturas, la producción se había paralizado y con esto una consecuente caída del mercado, de ahí que las obras que terminaron exportándose serían las que pertenecían a iglesias y particulares que no habían sido afectadas por la destrucción. El expolio herético y la exportación solapada de imágenes inglesas debió de ser bastante sustancioso si tenemos en cuenta que en la época de la Reforma el número de parroquias y capillas conventuales inglesas ascendía a más de diez mil, y que cada una de ellas debía de poseer al menos un retablo o imagen devocional ${ }^{15}$.

La furia iconoclasta protagonizada en suelo inglés por los exaltados seguidores de la Reforma alcanzó incluso a algunas obras de relativa calidad que habían llegado hasta nuestras tierras; en efecto, entre el dilatado elenco de destrozos imputados al saqueo de Drake en la villa de Vigo en el año 1598, figuraba un excepcional retablo gótico inglés de alabastro de singular calidad, procedente de algún oratorio o capilla privada inglesa, y que presidía el altar mayor de la Colegiata de Santa María, cuya descripción conocemos gracias a la información proporcionada por Santiago y Gómez en su Historia de Vigo. Afirma este autor, a propósito de la pieza en cuestión, que «...en la capilla mayor, a los dos lados del ábside había dos altares colaterales, uno de los cuales, que se nombraba San Benito, del lado del evangelio, era una perla, la verdadera joya de la iglesia, obra de reconocido mérito artístico, orgullo de los hijos de Vigo de aquel tiempo; me refiero al precioso retablo de alabastro blanco y dorado, que contenía en magnífico altorrelieve la Resurrección de Cristo, rodeada de escenas de la Pa-

Coruña en el año 1440, cuando el buque de peregrinos La Catherine fue apresado por los vecinos de A Coruña viéndose obligado a intervenir el arzobispo López de Mendoza quien, invocando los privilegios reales y la constitución de la Iglesia de Santiago, mandó liberarla inmediatamente y devolver al patrón los bienes que se le habían tomado. Ferreira Priegue, E.: Galicia en el comercio marítimo medieval, A Coruña: Fundación Pedro Barrié de la Maza, 1988, p. 577.

${ }_{14}$ Véase: Sánchez Ameijeiras, R.: «La importación de obras de arte en la Galicia Tardomedieval», en: Galicia Románica y Gótica, Galicia Terra Única, Ourense, 1997, pp. 310-314, esp. 312. Por esta vía llegó a Santiago de Compostela en el año 1456 el excepcional retablo gótico de alabastro inglés con escenas de la vida del Apóstol Santiago que un peregrino inglés llamado Johanes Gudguar, clérigo de Chal, en la isla de White, trajo consigo desde Inglaterra con el objeto de donarlo a la Catedral compostelana y que podemos ver actualmente en el Museo catedralicio. Sobre este retablo, véase: Hilburg, W.L.: «A datable english alabaster altarpiece at Santiago de Compostela», Antiquites Journal, 6, 1926, p. 304-307; Carro García, J.: «La vida de Santiago en un retablo del siglo XV», Correo Gallego, 25-07-1942; Hernández Perera, J.: 1956, p. 222; Alcolea, S.: «Relieves ingleses de alabastro en España. Ensayo de catalogación», Archivo Español de Arte, $\mathrm{n}^{\circ} 173-176,1971$, pp. 137-153, esp. P. 144; Cheetham, F.W.: 1984, pp. 22-23, 43-44, 47, 51, 59, 103, 335; Moralejo Álvarez, S.: «Retablo de la vida de Santiago ofrecido por John Goodyear», en Santiago, Camiño de Europa. Culto y Cultura en la Peregrinación a Compostela, Santiago de Compostela, 1993, pp. 506-507, $\mathrm{n}^{\circ} 181$; Manso Porto, C.: «Relevos e Retábulos. Imaxinería» en: Galicia Arte. Arte Medieval II, T. XI, A Coruña: Ed. Hércules, 1993, pp. 416-488, esp. pp. 422423.

${ }^{15}$ Cheetham, F.: 1984 , pp. 51-54.

AEA, LXXVII, 2004, 307, pp. 301 a 326 

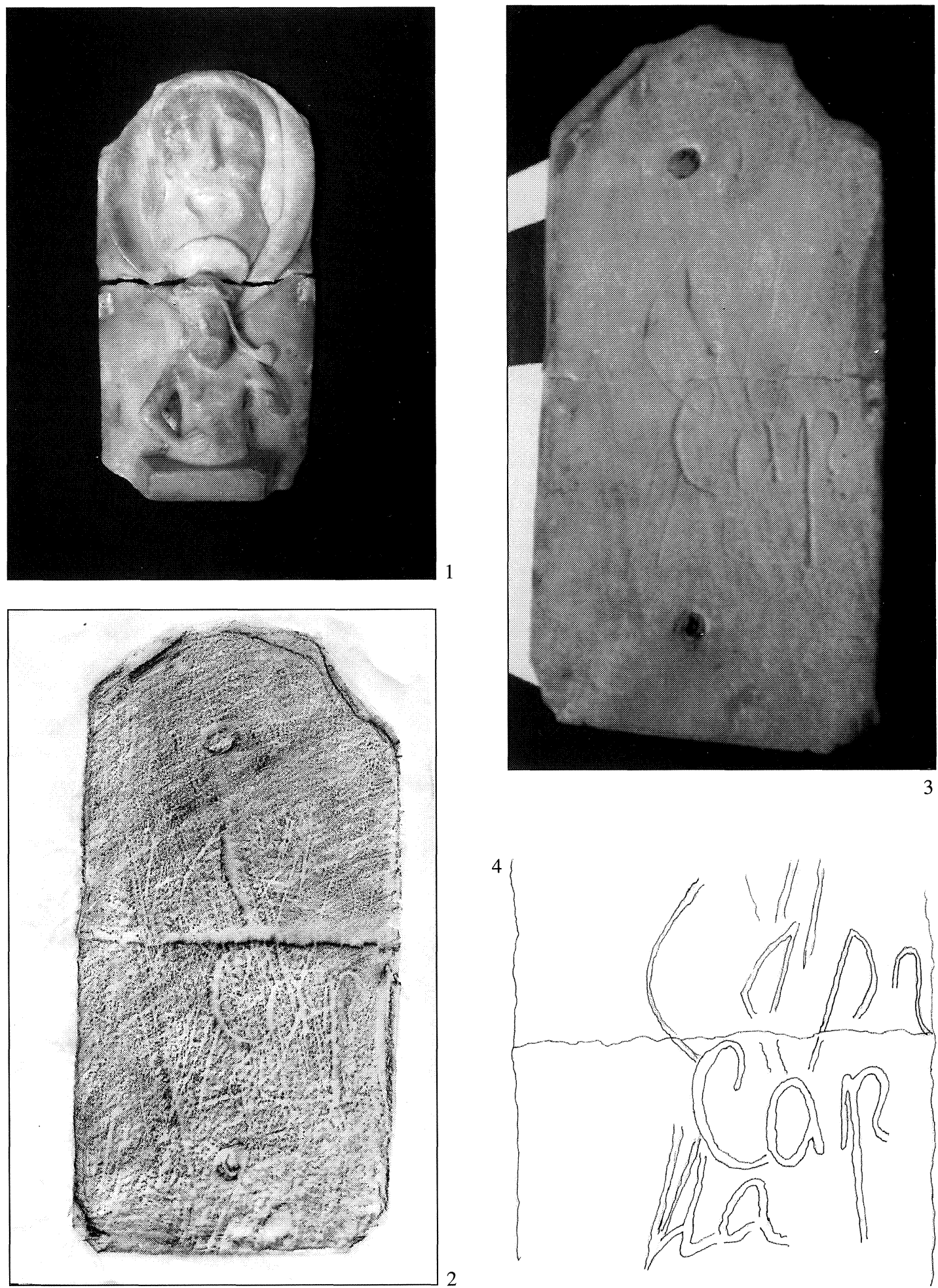

Fig.1 Cabeza de San Juan Bautista. Placa de alabastro procedente de la antigua Colección Massó. Finales del siglo xv Museo Massó (Bueu, Pontevedra). Fotografía: T. Moure.

Fig.2. Reverso de la placa de alabastro con inscripciones. Autor: T. Moure

Fig.3. Reverso de la placa de alabastro con inscripciones. Autor: T. Moure.

Fig.4. Calco de las inscripciones del reverso. Autor: T. Moure.

AEA, LXXVII, 2004, 307, pp. 301 a 326 
sión en bajorrelieve; según confesión de los que conocieron este retablo el sin número de esculturas y grupos artísticos de personajes bíblicos que representaba constituía una obra maestra de arte. La multitud de estas pequeñas figuras, por su estilo y por la época a que podía atribuirse su construcción y cincelado, debía tener un carácter semigótico que revelaba una mano maestra nada clásica. La donación de este artístico retablo se atribuía a un Árzobispo de Londres, y que procedía de la capilla del palacio de los reyes de Inglaterra, lo revelaba el magnifico escudo de armas que coronaba dicho altar» ${ }^{16}$. La escasez de datos no permite precisar mucho más en una aproximación al estudio artístico de este excepcional retablo. De todos modos, la reseña literaria es de gran valor ya que constituye el único testimonio conservado que hace referencia a este singular ejemplar.

Con seguridad, los años que siguieron a la Reforma debieron de ser los de mayor afluencia de imágenes religiosas a Galicia. El interés comercial primó sobre los atavismos religiosos, y la posibilidad de obtener un beneficio por la venta de un material que había quedado obsoleto salvó a muchas de estas obras de arte de su destrucción. En el año 1556, una indulgencia papal de Pablo IV permitía al obispo de Pontealegre (Portugal) don Julião de Alva adquirir prendas y objetos litúrgicos «ab ecclesias regnis anglicum», que eran vendidos por los marineros extranjeros en Lisboa ${ }^{17}$. Para Galicia no se ha encontrado de momento confirmación documental de estas ventas, si bien cabe la posibilidad de que fueran muy abundantes ${ }^{18}$; no obstante, podemos conjeturar que de esta manera podrían haber sido adquiridas algunas piezas de singular calidad como el retablo de alabastro con escenas de la vida de la Virgen de la catedral de Mondoñedo, el de la iglesia de Valcarría (Viveiro), con escenas de la Pasión de Cristo, conservado también en el museo catedralicio mindoniense ${ }^{19}$, o la Trinidad de la iglesia parroquial de San Ciprián de Vilanova de Arousa (Pontevedra) ${ }^{20}$, también imágenes de devoción de mayor tamaño como la de Nuestra Señora de Valdeflores que preside el retablo mayor de la iglesia del convento de Santa María de Valdeflores (Viveiro) ${ }^{21}$ o la imagen de Nuestra Señora la Inglesa de la catedral de Mondoñedo ${ }^{22}$. De igual manera, a comienzos del siglo XVI debió de llegar a Muros una importante partida de obras de arte adquiridas para decorar los altares de los templos de la zona y entre las que se encontraban tres retablos de alabastro

\footnotetext{
${ }^{16}$ Santiago y Gómez, S.: Historia de Vigo y su comarca, Madrid: Imprenta del Asilo de Huérfanos del Sagrado Corazón de Jesús, 1919, p. 258.

${ }^{17}$ Delaforce, A.: «Alabastros medievais ingleses en Portugal», en: Portugal e o Reino Unido. A Aliança Revisada, Lisboa: Fundaçao Calouste Gulbenkiam, 1995, p. 147.

${ }^{18}$ Poseemos testimonios bastante elocuentes del asentamiento de mercaderes ingleses en varios puntos de la costa gallega dedicados a la venta de paños que bien pudieron dedicarse al tráfico de obras de arte como los que se establecieron en la villa de Bayona y que firman sendos tratados comerciales en los años 1556 y 1564; Ramos, H.: Crónicas históricas de la villa de Bayona, Madrid, 1925, p.255.

${ }^{19}$ Sobre estas piezas me remito al reciente estudio, acompañado de amplia referencia bibliográfica, de Sánchez Ameijeiras, R.: «Devociones e imágenes medievales en la provincia de Mondoñedo», Estudios Mindonienses, 15, 1999, pp. 374409. Sobre los retablos del museo mindoniense véase también los siguientes estudios: Villa-Amil y Castro, J.: La catedral de Mondoñedo, su historia y descripción, sus pinturas murales, accesorios, mobiliario, bronce y orfebrería, vestiduras y ropas sagradas, Madrid, 1895; Alcolea, S.: 1971, 148-149; San Cristóbal Sebastián, S.: La ciudad de Mondoñedo, Ferrol, 1985, p. 61; López Morais, A y Casado Nieto, R.: Viaje por los pequeños museos de Galicia, León, 1989, pp. 204-207; Franco Mata, A.: El retablo gótico de Cartagena y los alabastros ingleses en España, Murcia: Caja de Ahorros de Murcia, 1999, pp. 45-74; Ídem, «El retablo de alabastro de Mondoñedo en el marco europeo», Miscelánea en honor de Monseñor Eugenio Romero Pose, Santiago de Compostela, 1999, pp. 927-952; Ídem, «El retablo de alabastro inglés de Santa María la Vieja de Cartagena y los retablos marianos en España», Boletín del Museo e Instituto "Camón Aznar», LXXXIII, 2001, pp. 109-172, esp. 126-133. 3-7.

${ }^{20}$ Valle Pérez, J.C.: «Un alabastro inglés en Vilanova de Arousa», Homenaje a Antonio Odriozola, El Museo de Pontevedra, XLIV, 1990, pp. 375-387.

${ }^{21}$ Sobre esta imagen: Manso Porto, C.: El arte de los dominicos en Galicia, II, La Coruña: Fundación Barrié de la Maza, 1993, p. 619; Idem, 1993, p. 443; Sánchez Ameijeiras, R.: 1999, p. 379-380.

${ }^{22}$ Lence Santar y Guitian, E.: «Nuestra Señora la Grande o la Inglesa de la catedral de Mondoñedo», Cuadernos de Estudios Gallegos, 1951, pp. 65-82; Sánchez Ameijeiras, R.: 1999, pp. 382-385.
}

AEA, LXXVII, 2004, 307, pp. 301 a 326 

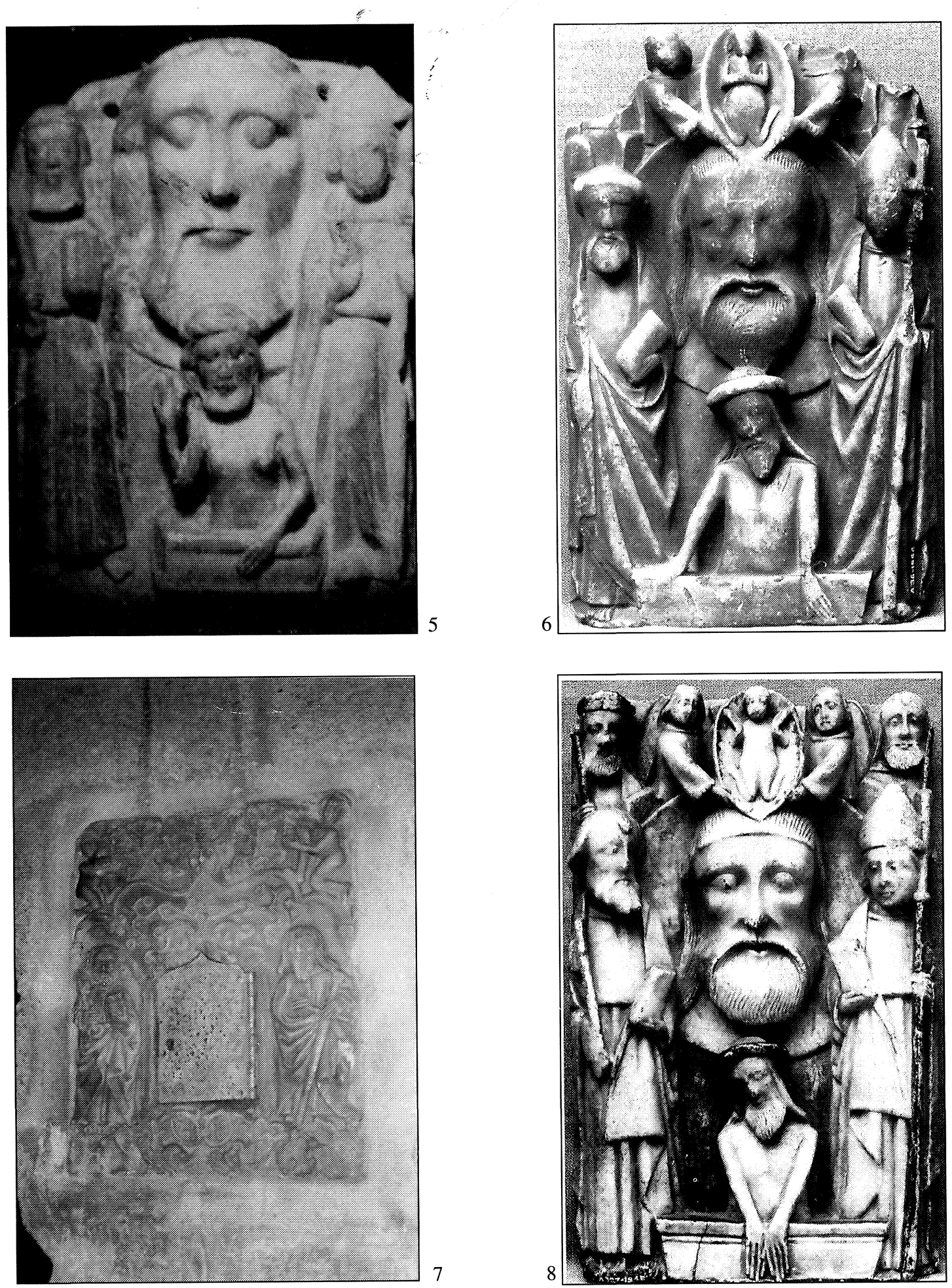

Fig.5. Cabeza de San Juan Bautista. Finales del siglo xv. Col. A. Manrique de Lara. Las Palmas de Gran Canaria. Fotografía: Hernández Perera.

Fig.6. Cabeza de San Juan Bautista. Finales del siglo XV. Victoria and Albert Museum. Fotografía: F. Cheetham. Fig.7. Alabastro inglés de la Colegiata de Xunqueira de Ambía. Finales del siglo XV. Colegiata de Xunqueira de Ambía (Orense). Fotografía: A. de la Peña.

Fig.8. Cabeza de San Juan Bautista. Finales del siglo xv. Victoria and Albert Museum. Fotografía: F. Cheetham.

AEA, LXXVII, 2004, 307, pp. 301 a 326 
-actualmente desaparecidos-, de los que hasta la fecha no teníamos constancia de su existencia y que conocemos gracias a la visita pastoral realizada el día 26 de abril del año 1547 por el licenciado Alfonso de Velasco. En su primera visita a la iglesia de San María del Campo, informa éste que su altar mayor «que es de piedra, consagrado» estaba enriquecido con la presencia de «un retablo de alabastro blanco de cinco historias». También la iglesia parroquial de San Pedro, hoy destruida, presumía de un altar mayor dotado de un nada modesto «retablo de cinco historias de mármol blanco, pequeñas, de bulto; la principal es la de la Trinidad ${ }^{23}$; y además, conforme nos certifica López Ferreiro, quien acertó a ver el documento original de la visita, «aún en la pequeña iglesia del Hospital había un retablo de cinco historias de mármol blanco, pequeñas de bulto» ${ }^{24}$.

A modo de conclusión, podemos exponer que la recuperación de esta serie de imágenes para la historia de arte gallego en general, contribuye no sólo a enriquecer el capítulo de imágenes de devoción importadas a Galicia sino también a confirmar el significativo auge que experimentó el tráfico de obras de arte de progenie inglesa a nuestras tierras entre los siglos xv y xVI. A los testimonios materiales, como hemos visto, hemos de sumar los testimonios escritos sobre imágenes tristemente desaparecidas y que constituyen una fuente primordial para el conocimiento de este patrimonio perdido.

Teresa C. Moure Pena

\footnotetext{
${ }^{23}$ Pérez Costanti, P.: «Una visita a las iglesias de Muros y otras, en 1547» en: Notas Viejas Galicianas, T. III, Vigo: Imprenta de los Sindicatos Católicos, 1926, pp. 47-51.

${ }^{24}$ López Ferreira, A.: Galicia Histórica, año I, Nov-Dic, nº 3, pp. 164-165.
}

AEA, LXXVII, 2004, 307, pp. 301 a 326 